\title{
Norois
}

Environnement, aménagement, société

$236 \mid 2015$

Présence chinoise en Arctique, nautisme, ville-port, vulnérabilité, inondation

\section{L'imaginaire géographique. Entre géographie, langue et littérature}

\section{Bertrand Guest}

\section{OpenEdition}

\section{Journals}

Édition électronique

URL : https://journals.openedition.org/norois/5733

DOI : $10.4000 /$ norois. 5733

ISBN : 978-2-7535-4945-6

ISSN : $1760-8546$

\section{Éditeur}

Presses universitaires de Rennes

\section{Édition imprimée}

Date de publication : 30 décembre 2015

Pagination : $91-93$

ISBN : 978-2-7535-4903-6

ISSN : 0029-182X

\section{Référence électronique}

Bertrand Guest, « L'imaginaire géographique. Entre géographie, langue et littérature », Norois [En ligne], 236 | 2015, mis en ligne le 01 juin 2016, consulté le 01 février 2022. URL : http://

journals.openedition.org/norois/5733; DOI : https://doi.org/10.4000/norois.5733

Ce document a été généré automatiquement le 1 février 2022

(C) Tous droits réservés 


\title{
L'imaginaire géographique. Entre géographie, langue et littérature
}

\author{
Bertrand Guest
}

\section{RÉFÉRENCE}

Lionel Dupuy, Jean-Yves Puyo, 2014. L'imaginaire géographique. Entre géographie, langue et littérature, Pau, PUPPA, coll. « Spatialités », 427 p.

1 Ce premier numéro de la collection «Spatialités " réunit les contributions d'une importante rencontre franco-luso-espagnole entre géographes, linguistes et littéraires. Livre frontalier et plurilingue bien qu'à dominante francophone (seuls deux chapitres sont en espagnol), il couvre tant par ses thématiques que par la situation de ses contributeurs un large espace pluriel dont la disparate même ouvre des pistes qu'un index aurait pu rendre encore plus fécondes. Il confronte des lectures de paysages et de textes menées par des chercheurs vivant aussi bien dans ces lieux qu'en dehors, écrivant ou non dans la langue d'écriture de ces textes, lesquels portent sur des espaces aussi bien proches que lointains; voilà qui donne au croisement de regards tout son sens. Du Pays basque d'Aurelia Arkotxa au Saint-Pétersbourg de Dostoïevski, les lieux visités sont toujours réels et imaginaires à la fois. Qu'il s'agisse de caractériser les projections exotiques d'un écrivain sur tel ailleurs ou de souligner la teneur géographique de telle description littéraire d'un espace habité par son auteur, l'ouvrage réaffirme - si besoin était - la participation de l'imaginaire à la réalité. Sous toutes ses formes, le récit ouvre la possibilité pour chacun d'interpréter le monde plutôt que d'en constater simplement les données factuelles, d'en avoir une connaissance sensible plutôt que chiffrée, d'entretenir la dimension humaine, intime ou affective qui est au cœur de tout lien entre les hommes et les lieux qu'ils traversent. Ce livre rappelle à juste titre combien la géographie est une écriture de la Terre et non simplement une «science » au sens restreint que lui donne le positivisme, «l'écriture et la connaissance [allant] de pair » comme l'écrit Vincent Berdoulay en préface. 
L'IMAGINAIRE GÉGRAPHIQUE

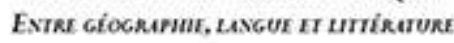

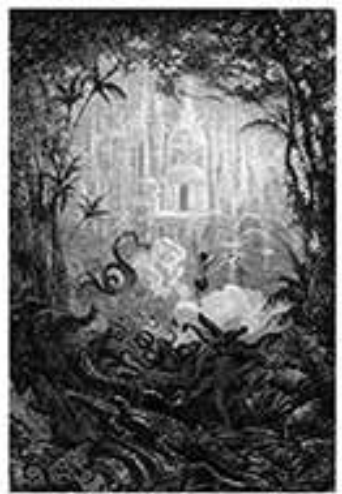

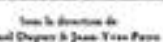

Les vingt-sept chapitres se répartissent en deux grands versants assez informels et peu apparents. Sous patronage vernien, les treize premiers engagent une réflexion sur l'imaginaire géographique en littérature à partir d'espaces «vécus, perçus et représentés » dans les romans du XIXe au XXe siècle (p. 29-222). La seconde partie part elle aussi de représentations de l'espace dans les romans, il est vrai plus troublées, pour envisager comme rétroactivement l'influence de la littérature sur les espaces réels (p. 223-416). C'est d'abord le roman d'aventures qui est exploré dans sa tension entre référents du monde réel et tentation de l'évasion, puis la carte en tant qu'elle sollicite l'imagination de son lecteur, de Huck Finn à l'Aldo du Rivage des Syrtes et au Marlow de Heart of Darkness. Dans Vendredi de Tournier et Malicroix de Bosco, le mythe de l'île déserte, tel que problématisé par la géographie, porterait une critique de la modernité. Les liens entre effet de réel et utopies concrètes sont un terrain qu'affectionne la fiction latino-américaine comme l'illustrent non seulement le Macondo de García Márquez, mais aussi le Mexico de Fuentes, le Chili de Contreras ou le monde hors-carte de Cortázar. À l'image du Doña Barbara de Gallegos participant à l'imaginaire vénézuélien des llanos, du mas nostalgique de Mistral en Provence ou de l'Âge d'Or gascon de Pesquidoux, l'œuvre littéraire peut s'inscrire dans un contexte nationaliste ou régionaliste sans toutefois jamais s'y résumer. La variété des démarches prime car si «c'est au moment où elle sort de la référence » que la géographie d'un Céline « touche au réel » (du Voyage au bout de la nuit à Casse-pipe), c'est au contact de modèles, de textes et d'auteurs géographiques (Ross, Reclus) que Verne chemine dans ses Voyages extraordinaires, d'où les nombreux travaux qui les mettent en regard des espaces référentiels « réels ». La Transylvanie ici particulièrement explorée est le berceau d'inépuisables topoï, de l'inversion réflexive, revers romantique ou « ailleursavant » de l'Occident chez Verne, au chronotope stéréotypique de la contrée hantée élaboré par Stoker. L'un des fils directeurs de la deuxième partie est incontestablement la profondeur diachronique, dès l'essai très porteur de Joan Tort-Donada consacré aux lieux, à la parole et à la mémoire, où l'on relit Machado, Maragall et Josep Pla pour qui « le paysage nous fait comprendre la littérature, celle-ci étant la mémoire du paysage à travers le temps ». Là où Saint-Pétersbourg se colore de la mémoire du crime de Raskolnikov, c'est celle d'une malédiction de l'entre-deux qui opère dans la Lotharingie mythique de Michel Louyot et Jean-Claude Pirotte. Se prolongeant jusqu'en Irlande, la 
Bretagne arthuro-gracquienne de Philippe Le Guillou est celle, réelle et fictionnelle à la fois, de l'enfance et des livres. Lieux de mémoire par excellence, recouverts de textes pas simplement d'ailleurs au sens de l'affichage publicitaire et citationnel par de grands architectes (chap. 15) - les villes que sont Brest, Marseille ou Rio de Janeiro n'occultent pas les espaces ruraux et forestiers, comme le Livradois, véritable personnage du très ethnologique et merveilleux Gaspard des montagnes de Pourrat. Face à la ville toute carcérale, la montagne est l'espace sans limites de la liberté chez Vallès, proche du Reclus d'Histoire d'une montagne et préfigurant l'exaltation du travail manuel rural comme perpétuation de mai 68 chez Alain Chany; frugal et fraternel partage. Le livre s'achève par une convaincante étude de l'éthique existentielle où se déploie le savoir géographique de Texaco (Chamoiseau). Outre le récit éthiopien des frères d'Abbadie, mélange d'orientalisme et de science, les essais paysagistes de Julio Llamazares consacrés à la Castille et au León et la poésie inclassable d'Arkotxa, la littérature reste majoritairement entendue en son sens répandu d'une bibliothèque de romans, comme si ce genre était le seul à y véhiculer des imaginaires géographiques en contact avec le réel. Éco-critiques et poéticiens, non représentés ici, insistent pourtant sur l'apport des textes non-fictionnels à une recomposition des rapports entre monde réel à décrire et monde idéal à construire, sans parler du Monde plausible (Westphal) malheureusement oublié. La question semble du coup parfois se restreindre à la mimésis plus ou moins fidèle du réel de référence ou à sa mise en images autour de motifs repérables (carte, île, forêt, ville, montagne), problèmes il est vrai fort subtilement traités. Bachelard et Butor, entre autres théoriciens de l'espace cités (De Certeau, Deleuze, Debarbieux, Said), dessinent un champ d'intersection dont l'équilibre reste relatif : il s'agit plus d'un livre de géographes (très supérieurs en nombre) prenant le roman pour terrain que de pensée indisciplinaire de l'espace, et l'on regrette l'absence d'un regard réciproquement porté sur ces fameux « concepts " géographiques dont on lit même ici ou là que la réflexion de tel roman manquerait (pour être pleinement une pensée, suppose-t-on?). Si ce livre s'inscrit avec force et justesse dans la nécessaire interdisciplinarité du "tournant spatial », c'est d'une façon peut-être encore trop inoffensive. À l'heure du storytelling de l'aménagement, on attendrait que l'analyse du discours ici mobilisée s'empare aussi des imaginaires géographiques à part entière que constituent les discours qui prétendent nous régir. Pour être plus récents et moins aisément identifiés comme tels, n'en sont-ils pas souvent d'autant plus puissamment actifs?

\section{AUTEURS}

\section{BERTRAND GUEST}

Université d'Angers 